\title{
A PRODUÇÃO DE UVA ORGÂNICA NO ESTADO DO RIO GRANDE DO SUL: AS EXPERIÊNCIAS DOS VITICULTORES DE COTIPORÃ, RS
}

\author{
The Production of Organic Grape in the State of the Rio Grande do Sul: the \\ experiences of the Cotiporã, RS grape growers
}

\author{
Vinício Luís Pierozan \\ Mestre em Geografia pelo Programa de Pós-Graduação em Geografia - POSGea/UFRGS \\ Universidade Federal do Rio Grande do Sul - UFRGS \\ vpierozan@hotmail.com
}

Recebido: 20/09/2019

Aceito: 29/11/2019

RESUMO: A produção de uva orgânica é pouco representativa frente o cultivo convencional em todo o mundo. A Itália com seus 60.000 (ha) de vinhedos orgânicos, que equivalem a aproximadamente $5,8 \%$ de toda a área cultivada com parreiras do país se constitui no maior produtor mundial de uva orgânica. No Brasil, o estado do Rio Grande Sul, responsável pela produção de $85 \%$ da uva e $90 \%$ do vinho nacional, tem sua produção concentrada na Serra Gaúcha, a produção de uva orgânica, por sua vez, é de aproximadamente $2 \%$ apenas. Porém, no município de Cotiporã, localizado na região serrana, vários agricultores familiares estão realizando o processo de conversão dos parreirais do sistema convencional para o orgânico. Assim, o objetivo deste artigo é analisar quais são as motivações que estão estimulando os agricultores a mudarem da produção de uva convencional para a produção de uva orgânica. $\mathrm{O}$ estudo foi baseado em pesquisa bibliográfica, trabalho de campo, aplicação de entrevistas semiestruturadas e coleta de dados em diferentes instituições. Concluiu-se que a produção de uva orgânica está se expandindo no município e os agricultores familiares que estão migrando para o cultivo orgânico buscam neste sistema de produção uma melhor valorização do seu trabalho e da fruta por eles produzida, que por consequência, traz maior rentabilidade e estabilidade financeira para o agricultor.

Palavras-chave: Viticultura Orgânica; Agricultura Familiar; Cotiporã-RS

\begin{abstract}
The production of organic grape is little representative front the conventional culture in the whole world. Italy with its 60,000 (ha) of organic vineyards, that are equivalent $5.8 \%$ of all approximately the area cultivated with vine arbors of the country if it constitutes in world-wide the producing greater of organic grape. In Brazil, the state of Rio Grande do Sul, responsible by the production of $85 \%$ of grape and $90 \%$ of the national wine, has its intent production in the Serra Gaúcha, the production of organic grape, in turn, it is of approximately only $2 \%$. However, in the city of Cotiporã, located in the mountain range "gaúcha" region, some familiar agriculturists are carrying through the process of conversion of the parreirais of the conventional system for the organic one. Thus, the objective of this article is to analyze which are the motivations that the agriculturists are stimulating to move of the production of conventional for the production of organic grape. The study it was based on Bibliographical research, work of field, application of semistructuralized interviews and collects of data in different institutions. It was concluded that the production of organic grape is if expanding in the city and the familiar agriculturists who are migrating for the organic culture they search in this system of production one better valuation of its work and the fruit for them produced, that for consequência, brings greater yield and financial stability for the agriculturist.
\end{abstract}

Keywords: Organic Viticulture; Familiar Agriculture; Cotiporã-RS 


\section{INTRODUÇÃO}

A produção de uva no estado do Rio Grande do Sul já está presente em 14.417 propriedades agrícolas que cultivam videiras, e juntas totalizam 40.336,22 (ha) de vinhedos distribuídos por 161 municípios (MELLO, et al., 2017a). Porém, existe uma forte centralização da viticultura no estado. A Microrregião de Caxias do Sul, que é composta por 19 municípios, concentra 79,68\% das propriedades vitícolas gaúchas que juntas possuem 32.305,98 (ha) de parreirais, totalizando $80,09 \%$ de toda a área ocupada com vinhas no estado (MELLO, et al., 2017a).

A Microrregião de Caxias do Sul, juntamente com os municípios vizinhos localizados na Encosta Superior da Região Nordeste do Rio Grande do Sul constituem um grupo de municípios que integram a Região da Serra Gaúcha1. Essa porção do território estadual foi colonizada por imigrantes italianos que começaram a chegar ao local a partir de 1875 e introduziram a cultura da videira e o hábito de consumir vinho no lugar (PIEROZAN; MANFIO, 2016), com o passar dos anos a tradição vitivinícola foi mantida, a uva se tornou o principal produto agrícola e o vinho o expoente máximo da cultura local.

A viticultura e o setor vinícola gaúcho, como um todo, encontram-se em fase de expansão no estado, novas áreas produtoras estão surgindo, outras estão ampliando os hectares cultivados, e as que produzem uva e vinho há mais tempo estão modernizando os seus processos produtivos desde a concepção e implantação dos vinhedos, início da cadeia produtiva, até os processos vínicos realizados nas cantinas familiares $^{2}$, vinícolas e demais empresas que processam a uva. Esse movimento se deu "A partir da década de 90, com a expansão das áreas cultivadas com uvas viníferas utilizadas para elaboração de vinhos finos e espumantes, que provocou uma mudança no perfil da atividade em muitos municípios produtores." (GARRIDO; JUNIOR, 2010, p.5).

Assim, dentro deste cenário de prosperidade da cadeia produtiva da uva e do vinho, tem-se visto nos últimos anos a produção de uva tornar-se importante como atividade agrícola e ganhar relevância econômica também na Região da Campanha Gaúcha ${ }^{3}$ e

\footnotetext{
1 Se constitui numa "denominação regional" para designar a Encosta Superior da Região Nordeste do Rio Grande do Sul. Todavia, analisando-se a partir da perspectiva geomorfológica, o que é denominado de Serra é na realidade parte das escarpas dissecadas do Planalto Basáltico Sul-Riograndense ou Serra Geral (AB'SÁBER, 2003).

${ }^{2}$ As cantinas eram compartimentos de pedra (basalto) situados embaixo da casa de moradia (porão das casas) onde ficavam as pipas e os instrumentos necessários à fabricação do vinho (TAVARES DOS SANTOS, 1978, p.74). As cantinas foram empreendimentos bastante comuns nas regiões de colonização italiana no Sul do país, com o passar dos anos a maior parte delas foram sendo transformadas em pequenas vinícolas familiares. Porém, hoje em dia, ainda existem agricultores familiares que as mantém nos porões de suas casas, principalmente nos municípios da Serra Gaúcha. ${ }^{3}$ De acordo com o Instituto Brasileiro de Geografia e Estatística (IBGE) a Campanha Gaúcha está localizada na Mesorregião Sudoeste Rio-Grandense sendo formada por dezenove municípios, subdivididos em três microrregiões: Campanha Central, Campanha Meridional e Campanha Ocidental (IBGE, 2006, p.34).
}

REVISTA GEONORTE, V.10, N.36, p.17-35, 2019.

DOI: 10.21170/geonorte.2019.V.10.N.34.A17.35

(ISSN 2237 - 1419) 
na Microrregião Serras do Sudeste ${ }^{4}$. Nessas regiões a produção de uva foi favorecida principalmente pelas condições favoráveis do lugar que facilitam o plantio dos vinhedos como o solo, as horas de insolação diária, o clima, a disponibilidade de terras agricultáveis e o relevo plano, levemente ondulado, que favorece a mecanização e a utilização de aparatos tecnológicos modernos nos parreirais (MELLO et al., 2017a). Somam-se também, a estes fatores de ordem natural e física dessas regiões geográficas, a produção de uva e vinho como uma forma de diversificar a produção agrícola das propriedades rurais; a pretensão de empresas já estabelecidas em ampliar seus negócios e/ou aumentar a sua participação no mercado; a oportunidade surgida para a agricultura familiar; 0 interesse despertado em investidores/conhecedores de vinho capitalizados que vislumbraram um nicho de mercado com grandes perspectivas de crescimento no país para os próximos anos.

Destaca-se que a produção de uvas no estado, é em sua maior parte, realizada dentro do paradigma convencional de agricultura, que faz a utilização intensiva de agrotóxicos e adubos sintéticos nos vinhedos. A área de estudo, município de Cotiporã, também está inserida dentro desta lógica de produção agrícola.

Os vinhedos localizados em Cotiporã são amplamente cultivados de acordo com o modelo da agricultura convencional, que adere aos pacotes tecnológicos fortemente difundidos no Brasil a partir da década de 1960, através da Revolução Verde 5 . Todavia, um grupo de agricultores familiares localizados no interior do município estão buscando novas alternativas para produzir uvas, com vistas a romper com o modelo de produção agrícola hegemônico. Assim, alguns agricultores passaram e outros estão em processo de transição agroecológica para converter os vinhedos do sistema convencional para o modelo de produção orgânica.

O presente artigo objetiva entender quais são as motivações que estão estimulando os agricultores familiares a mudarem da produção de uva convencional para a produção de uva orgânica no município de Cotiporã. A produção de uva é a principal atividade agrícola do município, que tem a sua economia totalmente baseada na agricultura familiar e na pequena propriedade rural. Na safra $2016-2017^{6}$, foram

\footnotetext{
${ }^{4}$ Está localizada na Mesorregião do Sudeste Rio-Grandense sendo formada por oito municípios: Encruzilhada do Sul, Candiota, Pinheiro Machado, Piratini, Caçapava do Sul, Santana da Boa Vista, Amaral Ferrador e Pedras Altas (MATTE; WAQUIL; NESKE, 2014).

${ }^{5}$ A Revolução Verde [...] se apoia em três "princípios", todos para criar dependência e, portanto, custos para o produtor: fertilizantes de síntese química - ureia, superfosfatos, cloreto de potássio e tantos outros - , venenos contaminantes da vida humana e da vida ambiente (agrotóxicos) e as monoculturas que destroem a biodiversidade e, consequentemente, os biomas (MACHADO; MACHADO FILHO, 2014, p.61).

${ }^{6}$ No Rio Grande do Sul, o período de colheita da uva (vindima), tem início no final de novembro com a variedade super precoce Vênus e se prolonga até o final do mês de março do ano seguinte com a colheita das cultivares mais tardias, sendo realizada uma única safra ao ano. Todavia, nas demais regiões brasileiras produtoras de uva o período da vindima e a quantidade de safras anuais é variável pois, depende das condições climáticas do lugar e da tecnologia utilizada nos vinhedos. No Vale do
}

REVISTA GEONORTE, V.10, N.36, p.17-35, 2019.

DOI: 10.21170/geonorte.2019.V.10.N.34.A17.35

(ISSN 2237 - 1419) 
colhidas 23.556.086,63 $(\mathrm{Kg})$ da fruta, que coloca o município entre os maiores produtores de uva no estado do Rio Grande do Sul, na décima colocação (IBRAVIN, 2017, on-line).

Para dar conta do objetivo proposto utilizou-se como trajetória metodológica a pesquisa de caráter qualitativo, revisão de material bibliográfico e posterior análise, aplicação de entrevistas semiestruturadas e trabalho de campo. Inicialmente foi realizada a consulta bibliográfica com o objetivo de direcionar a construção teórica do artigo. Posteriormente foram realizadas visitas a entidades que apoiam, incentivam e são parceiras dos agricultores orgânicos como, por exemplo, a Empresa de Assistência Técnica e Extensão Rural - EMATER/RS (escritório de Cotiporã) e a Prefeitura Municipal de Cotiporã - PMC. Em campo, foram visitadas dez unidades de produção agrícolas para aplicar entrevistas, coletar informações, e demais dados relevantes para o estudo. Por fim, realizou-se a análise das informações, materiais e dados coletados.

Justifica-se este estudo pela necessidade de promover novas formas de produzir uva como, por exemplo, a produção orgânica, num dos municípios de maior produção da fruta no estado, que tem sua produção fortemente concentrada no cultivo convencional. Este modelo agrícola mantém o agricultor totalmente dependente dos agrotóxicos e fertilizantes elaborados pela indústria química e subordinado as políticas de preço e qualidade impostas pelas grandes vinícolas que dominam o mercado vitivinícola. Dessa forma, a viticultura orgânica busca proporcionar novas alternativas para o agricultor familiar continuar produzindo uva sem a interferência dos grandes agentes econômicos que ditam as regras para o setor.

Para um melhor entendimento do artigo, o texto encontra-se estruturado em quatro diferentes partes: a primeira é a guisa teórica, envolve uma reflexão sobre a agricultura convencional e a agricultura orgânica; a segunda compreende uma análise em relação a produção de uva orgânica e seus subprodutos no estado do Rio Grande do Sul; a terceira contempla o processo de conversão da produção de uva convencional para a produção de uva orgânica por parte dos agricultores de Cotiporã; a quarta tece as considerações finais.

\section{À GUISA TEÓRICA}

A agricultura convencional também designada como agricultura industrial tem proporcionado ao longo das últimas décadas no campo brasileiro "[...] aumentos significativos de produtividade dos cultivos e formado sistemas "aparentemente" rentáveis [...]" (ABREU et al., 2012, p.144). Porém, esse modelo de agricultura acentuou e/ou trouxe consigo uma série de problemas para o espaço rural que

Submédio São Francisco, por exemplo, compreendendo o polo Petrolina-Juazeiro, estado de Pernambuco e Bahia, com a utilização da irrigação podem ser realizadas até 3 safras anuais.

REVISTA GEONORTE, V.10, N.36, p.17-35, 2019.

DOI: 10.21170/geonorte.2019.V.10.N.34.A17.35

(ISSN 2237 - 1419) 
competem à ordem social, política, ambiental, econômica e de segurança (violência), que vitimou e vitima, principalmente os menos favorecidos como, por exemplo, os agricultores familiares, os povos indígenas, os agricultores sem terra, os defensores e militantes da reforma agrária, as comunidades tradicionais e ribeirinhas que querem e desejam um espaço agrário destinado a produção de alimentos e não simplesmente para a reprodução do capital, através de monocultivos destinados a abastecer o mercado internacional de commodities ${ }^{7}$ agrícolas.

\title{
A agricultura convencional provoca e ocasiona
}

\begin{abstract}
dependência crescente de combustíveis fósseis e a baixa eficiência energética; a degradação dos recursos naturais, contaminação de alimentos e meio ambiente; o uso crescente de agrotóxicos (inseticidas, herbicidas, fungicidas) e fertilizantes químicos; o impacto negativo sobre a saúde dos agricultores e dos consumidores; a erosão genética (perda de variedades crioulas); diminuição da biodiversidade com a simplificação dos agroecossistemas; a perda de técnicas, da cultura e de saberes tradicionais dos agricultores; e, finalmente, o aumento do êxodo e da pobreza rural (SARANDON, 2009, citado por ABREU et al., 2012, p.144).
\end{abstract}

De acordo com Queiroz (2014) o Brasil é um dos países que detém o maior consumo de fertilizantes utilizados na agricultura, que em sua maior parte, são produtos importados, fato que cria grande dependência do país com o mercado internacional. No cenário interno, $82 \%$ do mercado de fertilizantes é controlado por apenas 4 empresas privadas que juntas mantêm a concentração da produção das matériasprimas utilizadas para a fabricação dos adubos agrícolas. Os venenos, por sua vez, já tornaram o país "[...] o maior consumidor de agrotóxicos do mundo desde 2008 [...]" (FREITAS; BOMBARDI, 2018, p.86), somente na América Latina o Brasil consome a incrível marca de $84 \%$ dos venenos comercializados entre todos os países latinos para serem aplicados nos cultivos agrícolas (PELAEZ, 2011). Em contrapartida, na Europa, "Dos 504 agrotóxicos liberados no Brasil, 30\% são proibidos na União Europeia pelos riscos que oferecem à saúde e ao meio ambiente." (PADOVAN, 2018, on-line).

A propriedade e o uso da terra no país também são preocupantes, $76 \%$ das terras agricultáveis estão sendo utilizadas pela agricultura agroindustrial empenhada em produzir commodities tendo por base o latifúndio, os outros $24 \%$ das terras são ocupadas por $84 \%$ dos proprietários rurais, que se constituem, em sua maior parte, agricultores familiares, que produzem $70 \%$ dos alimentos consumidos pela população brasileira (TOLEDO; BARRERA-BASSOLS, 2015).

O modelo convencional de agricultura que atualmente é dominante e vastamente utilizado ao longo de todo o território brasileiro foi fortemente incentivado e estimulado

\footnotetext{
7 No singular commodity, é um vocábulo da língua inglesa que significa mercadoria (produto). As commodities (plural) tratam-se de mercadorias destituídas de seu valor de uso. $O$ valor de uso (pensado, segundo Marx (1982), enquanto propriedades físicas e intrínsecas ao objeto) no caso do alimento se perde, ou se transmuta, quando este se transforma em commodity, ou seja, em um tipo de mercadoria - para além da sua característica enquanto alimento - permite que seja negociada no mercado global como quaisquer outras. Ao se transformar em commodity, e mesmo em energia, o alimento tem destituído (ou deslocado do primeiro plano) o seu valor de uso enquanto forma de alimentação humana (BOMBARDI, 2017, p.25).
}

REVISTA GEONORTE, V.10, N.36, p.17-35, 2019.

DOI: 10.21170/geonorte.2019.V.10.N.34.A17.35

(ISSN 2237 - 1419) 
no país com grande vulto no final da década de 1960, e principalmente a partir de 1970 em diante, pelo governo da época, que via a agricultura convencional como sinônimo de crescimento econômico e progresso (CONTERATO; FILIPI, 2009). Esse movimento verificado no espaço agrário brasileiro recebeu a denominação de "[...] modernização conservadora, visava acelerar a modernização da agricultura com base na grande propriedade, através da criação de um sistema de créditos e subsídios." (FERNANDES, 2000, citado por MEDEIROS; LINDNER, 2014, p.263, grifos do autor). De tal modo, que

[...] o uso de agrotóxicos passou a ser disseminado e incentivado no Brasil, resultante do avanço do capitalismo no campo, amparado pelo discurso de ampla produtividade da agricultura, sob a prelação do remate da fome, questão não solucionada, mesmo após intensa produtividade agrícola (FREITAS; BOMBARDI, 2018, p.89).

Contudo, com o passar dos anos e diante de todos os encalços anteriormente citados que começaram a se proliferar e instaurar no campo com a adoção da agricultura convencional vários movimentos sociais como, por exemplo, o Movimento dos Trabalhadores Rurais Sem Terra - MST, Organizações não Governamentais - ONGs e agricultores familiares passaram a buscar diferentes maneiras para produzir alimentos sem a utilização de venenos, fertilizantes químicos e demais produtos fomentados pela indústria química. Assim, dentro deste contexto de mudança de paradigma agrícola passa a ganhar importância a agricultura orgânica que

[...] pode auxiliar o desenvolvimento rural, principalmente de comunidades de agricultores familiares, em decorrência da baixa dependência por insumos externos, pela alta preservação ambiental que proporciona e pelo aumento de valor agregado ao produto com consequente aumento de renda do agricultor. Atualmente, é alternativa em ampla expansão no plano mundial, sendo preconizada, por diversos segmentos sociais, como opção para a promoção do desenvolvimento agrícola sustentável (DE-POLLI et al., 2000, p.1).

A agricultura orgânica passa a utilizar técnicas que levam em consideração a relação estabelecida através do tripé "solo, planta, ambiente", onde também é considerado igualmente importante, cuidar da saúde e do bem estar dos homens, animais e preservar os recursos naturais (MEIRELES; RUPP, 2014). O enfoque da agricultura orgânica vai muito além da simples não utilização de agrotóxicos, fertilizantes e demais produtos químicos elaborados pela indústria para serem usados nos cultivos agrícolas, a agricultura orgânica leva em consideração, além disso, múltiplos aspectos

[...] que numa abordagem mais ampla, são tão relevantes para a humanidade e o meio ambiente quanto a composição química dos alimentos cultivados sob esta perspectiva: o respeito ao ambiente, o cuidado com o solo que é entendido como um organismo vivo onde a diversidade de formas de vida está presente, o respeito ao ciclo natural de desenvolvimento das plantas e animais, bem como o estabelecimento de relações justas de produção e consumo são aspectos fundamentais que tornam a agricultura orgânica tão relevante para os dias atuais, e que não por acaso, tem atraído cada vez mais consumidores interessados no consumo destes alimentos (QUEIROZ, 2014, p.2). 
No cenário internacional Vilela et al. (2019) salienta que, dados referentes ao acompanhamento da agricultura orgânica praticada em 178 países no ano de 2018 , este cultivo ocupava

[...] 57,8 milhões de hectares, que correspondem a $1,2 \%$ das áreas produtoras do mundo, e representa 2,7 milhões de produtores orgânicos. Esse universo correspondia a um mercado de US\$ 89,7 bilhões em 2016, liderado por EUA (US\$ 43,1 bilhões), Alemanha (US\$10,5 bilhões) e França (US $\$ 7,5$ bilhões) (VILELA et al., 2019, p.9).

A agricultura orgânica nacional também está aumentando a sua participação na produção de alimentos saudáveis. Em 2013 existiam no país 5.073 produtores orgânicos cadastrados no Ministério da Agricultura, Pecuária e Abastecimento MAPA, em 2018 o número de produtores orgânicos cadastrados aumentou consideravelmente e passou a contar com 16.710, totalizando um aumento de mais de 329\% no número de produtores orgânicos cadastrados em apenas 5 anos (EDUARDO; FINATTO, 2018).

No que tange ao consumo dos produtos oriundos da agricultura orgânica no Brasil, um recente estudo realizado em 2017 pelo Conselho Brasileiro da Produção Orgânica e Sustentável - ORGANIS, apontou que a principal motivação para $60 \%$ dos brasileiros que consomem alimentos orgânicos no país reside nos benefícios que esses produtos trazem para a saúde juntamente com a preservação ambiental que o cultivo orgânico proporciona para o ambiente onde é cultivado (ORGANIS, 2017). Os alimentos orgânicos mais consumidos pelos brasileiros são: as verduras e legumes, principalmente a alface (mais consumida), tomate, rúcula, brócolis; as frutas com destaque para a banana, a maçã e os sucos orgânicos; dentre os cereais o arroz aparece com frequência na cesta básica dos consumidores (ORGANIS, 2017).

\section{A PRODUÇÃo E A EXPANSÃO DO CULTIVO DE UVA ORGÂNICA E SEUS SUBPRODUTOS NO ESTADO DO RIO GRANDE DO SUL}

A produção de uva orgânica no Brasil ainda é pequena, e as informações a respeito são esparsas e pouco consistentes. De qualquer forma, sabe-se que existem iniciativas de produção orgânica de uva em praticamente todos os estados produtores (CAMARGO; TONIETTO; HOFFMANN, 2011, p.148). A viticultura orgânica praticada no Rio Grande do Sul e, em particular, a que ocorre nos municípios que fazem parte da Serra Gaúcha, território vitivinícola nacional internacionalmente reconhecido principalmente pelos seus vinhos e espumantes, produzem uvas destinadas sobretudo para o consumo in natura e para a elaboração de sucos, tendo por base as cultivares americanas e híbridas (uva comum), variedades mais rústicas e resistentes ao ataque de pragas e doenças que acometem a videira. A Federação das Cooperativas Vinícolas do Rio Grande do Sul (FECOVINHO), salienta que nessa região "[...] o principal produto orgânico é a uva, especialmente a destinada para suco de uva orgânico, envolvendo mais de 20 processadores de sucos, entre cooperativas e empresas vinícolas da região." (FECOVINHO, 2016, p.3). 
Melo, Botton e Garrido (2015, p.9) destacam que, "A viticultura orgânica está em franco crescimento na região da Serra Gaúcha, tanto na produção como também no consumo de frutos e de produtos processados." Já Giovannini (2001, p.4) acrescenta que, "[...] com cultivares americanas vem sendo possível o cultivo agroecológico, com a manutenção e até pequenos aumentos de produtividade e uva de mesma qualidade [...] substituindo o convencional." Já a produção orgânica com as cultivares europeias, Vitis vinífera, mais bem utilizadas para a elaboração de vinhos finos é pouco expressiva no estado quando comparada com a produção orgânica dos vinhedos cultivados com as variedades americanas e híbridas e não existe um controle estatístico da quantidade produzida (t) e área cultivada (ha).

Segundo o Centro Ecológico de Ipê (2017), atualmente existem na Serra Gaúcha, 342 produtores de uva certificados. Alguns são exclusivamente viticultores, mas a grande maioria deles se dedicam também a outras atividades agrícolas e nãoagrícolas, ou seja, os produtores de uva orgânica buscam diversificar a sua produção em sua unidade de produção agrícola e na medida do possível procuram evitar o monocultivo. Todavia, os que se atém exclusivamente à produção de uva, boa parte deles, se dedicam à viticultura há décadas, é um cultivo que faz parte da tradição cultural da família e passa de pai para filho (MANFIO; PIEROZAN; MEDEIROS, 2019).

A produção de uva orgânica na safra 2016-2017 para a região da Serra Gaúcha totalizou 11 milhões de quilos, enquanto a viticultura convencional produziu 753.279.645 quilos de uva9. A partir desses dados constata-se que, a produção orgânica correspondeu a 1,47\% em relação ao cultivo que utiliza agroquímicos para a safra do mesmo ano correspondente. Porém, a quantidade produzida pode ser bem maior, pois no "[...] caso da uva orgânica, grande parte da produção provém da agricultura familiar, cuja comercialização ocorre em feiras, diretamente ao consumidor. Isto tem dificultado o controle estatístico da produção." (CAMARGO; TONIETTO; HOFFMANN, 2011, p.148).

Nas demais regiões do estado gaúcho não existem informações disponíveis referentes a quantidade produzida (t), área cultivada (ha) com parreirais e as variedades cultivadas no sistema orgânico, bem como, a quantidade da fruta que é processada pela indústria vinícola e/ou agricultores familiares em suas próprias propriedades. A exceção ocorre na região da Campanha Gaúcha, onde "Os produtores familiares estão montando um sistema de infraestrutura própria para atender a atividade da vitivinicultura orgânica." (PIEROZAN; MANFIO, 2016, p.s/n). Essa iniciativa por parte dos agricultores familiares visa aproveitar as novas oportunidades que estão surgindo na região devido a expansão de vinhedos comerciais e empreendimentos vitivinícolas sofisticados voltados a produção de vinhos finos. A produção orgânica foi a alternativa encontrada pelos agricultores

\footnotetext{
8 Os dados referentes a produção orgânica de uva cultivada na Serra Gaúcha foram disponibilizados pela ONG Centro Ecológico de Ipê (Núcleo Serra) pelo coordenador da instituição, Leandro Venturin, que mantém acompanhamento, fornece capacitações e presta assessoramento junto aos produtores rurais e associações de agricultores familiares, que produzem uva na forma orgânica em toda a Serra Gaúcha.

9 Produção total de uva comercializada nas empresas de beneficiamento (vinícolas, cooperativas e fábricas de sucos) gaúchas durante a safra 2016-2017 (IBRAVIN, 2017, on-line).
}

REVISTA GEONORTE, V.10, N.36, p.17-35, 2019.

DOI: 10.21170/geonorte.2019.V.10.N.34.A17.35

(ISSN 2237 - 1419) 
familiares, descapitalizados e/ou com dificuldades de acesso a linhas de crédito em instituições financeiras também se inserirem na produção de uva e seus subprodutos. No âmbito institucional o Programa Quintais Orgânicos de Frutas ${ }^{10}$, também está estimulando a produção de uva, suco de uva e vinho orgânico no município de Dom Pedrito, bem como a comercialização dos mesmos pelos próprios agricultores (MANFIO; PIEROZAN; MEDEIROS, 2019).

A concentração e o fortalecimento da produção de uva orgânica na Serra Gaúcha são alicerçados principalmente pelo grande e forte arranjo institucional existente entre empresas públicas e privadas de pesquisa e extensão rural, Organizações Não Governamentais (ONGs), entidades representativas do setor vitivinícola e dos agricultores produtores de uva. As principais instituições que fomentam e mantém projetos voltados à produção orgânica de uva, vinho, suco de uva e demais produtos feitos a partir da uva orgânica são: a Empresa Brasileira de Pesquisa Agropecuária (EMBRAPA Uva e Vinho); a Empresa de Assistência Técnica e Extensão Rural (EMATER-RS); a Federação das Cooperativas Vinícolas do Rio Grande do Sul (FECOVINHO); o Instituto Federal de Educação Ciência e Tecnologia do Rio Grande do Sul (IFRS Campus Bento Gonçalves); o Instituto Brasileiro do Vinho (IBRAVIN); a Cooperativa de Sucos Monte Vêneto; o Centro Ecológico de Ipê e a Rede Ecovida de Agroecologia; entre outras (PIEROZAN; MANFIO; MEDEIROS, 2018, p.2622).

Em relação aos vinhos orgânicos ${ }^{11}$, a produção nacional ocorre em pequena escala, numa quantidade bastante reduzida quando comparada à produção convencional e à produção realizada por países que possuem tradição vitivinícola ${ }^{12}$. Em nível global, os maiores produtores de uvas orgânicas são países que possuem séculos de experiência com o cultivo de vinhedos e elaboração de vinhos e, estão localizados principalmente no continente europeu. Atualmente, os três maiores produtores mundiais de uva orgânica são Itália, Espanha e França (LUIZZI; FERREIRA; SCHNEIDER, 2016).

A Itália, "[...] conta atualmente com 5,8\% de sua área agrícola destinada aos vinhedos cultivados utilizando este método (sobretudo no Vêneto e na Sicília), o que equivale a 60.000 hectares de vinhedos orgânicos cultivados [...]." (CELENTANO, 2018). Em relação ao setor vitivinícola internacional

Hoje, $4 \%$ da produção mundial é de vinho orgânico, inclusive no novo mundo - a Argentina, com produtores como Norton e família Zuccardi, o Chile, em

10 Projeto desenvolvido pela EMBRAPA (Clima Temperado). Esse projeto foi selecionado para participar da "Plataforma de Boas Práticas para o Desenvolvimento Sustentável", que integra o programa de cooperação internacional com a Organização das Nações Unidas para a Alimentação e a Agricultura - FAO (EMBRAPA, 2016).

${ }^{11}$ A produção de vinhos orgânicos no Brasil ainda é pouco significativa frente o sistema convencional, e não existem dados disponíveis em relação a quantidade de litros produzidos e consumidos em nível nacional. Todavia, a produção de uvas destinadas a elaboração de vinhos orgânicos se situa em torno de $1 \%$ do cultivo de Vitis viníferas. No Rio Grande do Sul, maior produtor nacional, em 2017 foram processados 1,5 milhão de quilos de uva orgânica destinada exclusivamente a elaboração de vinhos orgânicos (CAETANO, 2017).

12 Atualmente a Itália é o maior produtor mundial de vinhos orgânicos, com uma produção estimada entre 3 e $4 \%$ de toda a produção de vinhos do país (CELENTANO, 2018).

REVISTA GEONORTE, V.10, N.36, p.17-35, 2019.

DOI: 10.21170/geonorte.2019.V.10.N.34.A17.35

(ISSN 2237 - 1419) 
bodegas como a Viña Carmen e o Brasil com Juan Carrau, que em 1997 lançou o primeiro vinho orgânico do Brasil (CELENTANO, 2018).

A viticultura, orgânica prima pela eliminação dos resíduos tóxicos dos parreirais, onde a uva é cultivada, procura o equilibro biológico do ambiente, valorizando e buscando benefícios para a produção de alimentos mais saudáveis para o consumo, e também se preocupa com a saúde de quem os cultiva, pois ambos devem estar em sintonia, equilíbrio. Nesse sentido, a agricultura orgânica utiliza também pressupostos teóricos da agroecologia, que podem estar presentes no cultivo orgânico em diferentes níveis, que segundo Giovannini (2001, p.10)

[...] para produção de uva consiste na observância e aplicação de um conjunto de técnicas em que o produto final seja o resultado da interação simultânea de diversos aspectos que propiciem o equilíbrio nutricional, bioquímico-fisiológico da planta. Esse depende em grande parte do equilíbrio químico e sobretudo do equilíbrio físico e biológico do organismo vivo do solo, dependendo também em maior ou menor grau do equilíbrio do ecossistema e das condições climáticas.

Acrescenta-se também, além da preocupação ambiental, as questões que dizem respeito a ordem social, econômica, política e culturais, que devem ser contabilizadas, quando se deseja produzir uvas orgânicas para que a viticultura seja ecologicamente sustentável e economicamente viável para os agricultores familiares.

\section{DA PRODUÇÃO DE UVA CONVENCIONAL À ADOÇÃO DA VITICULTURA ORGÂNICA NO MUNICÍPIO DE COTIPORÃ}

O município de Cotiporã (Figura 1) está localizado na Mesorregião Nordeste RioGrandense, pertencente a Microrregião de Caxias do Sul, e juntamente com mais 47 municípios constitui a Região da Serra Gaúcha (IBGE, 2011, on-line). Segundo o Censo Demográfico realizado pelo IBGE em 2010 a população total do município era composta por 3.917 habitantes, sendo 2.033 do sexo masculino e 1.884 do gênero feminino. Desses moradores, 2.048 residiam no perímetro urbano e 1.869 moravam na área rural do município, a taxa de urbanização de Cotiporã é de 52,28\% (IBGE, 2010, on-line). 

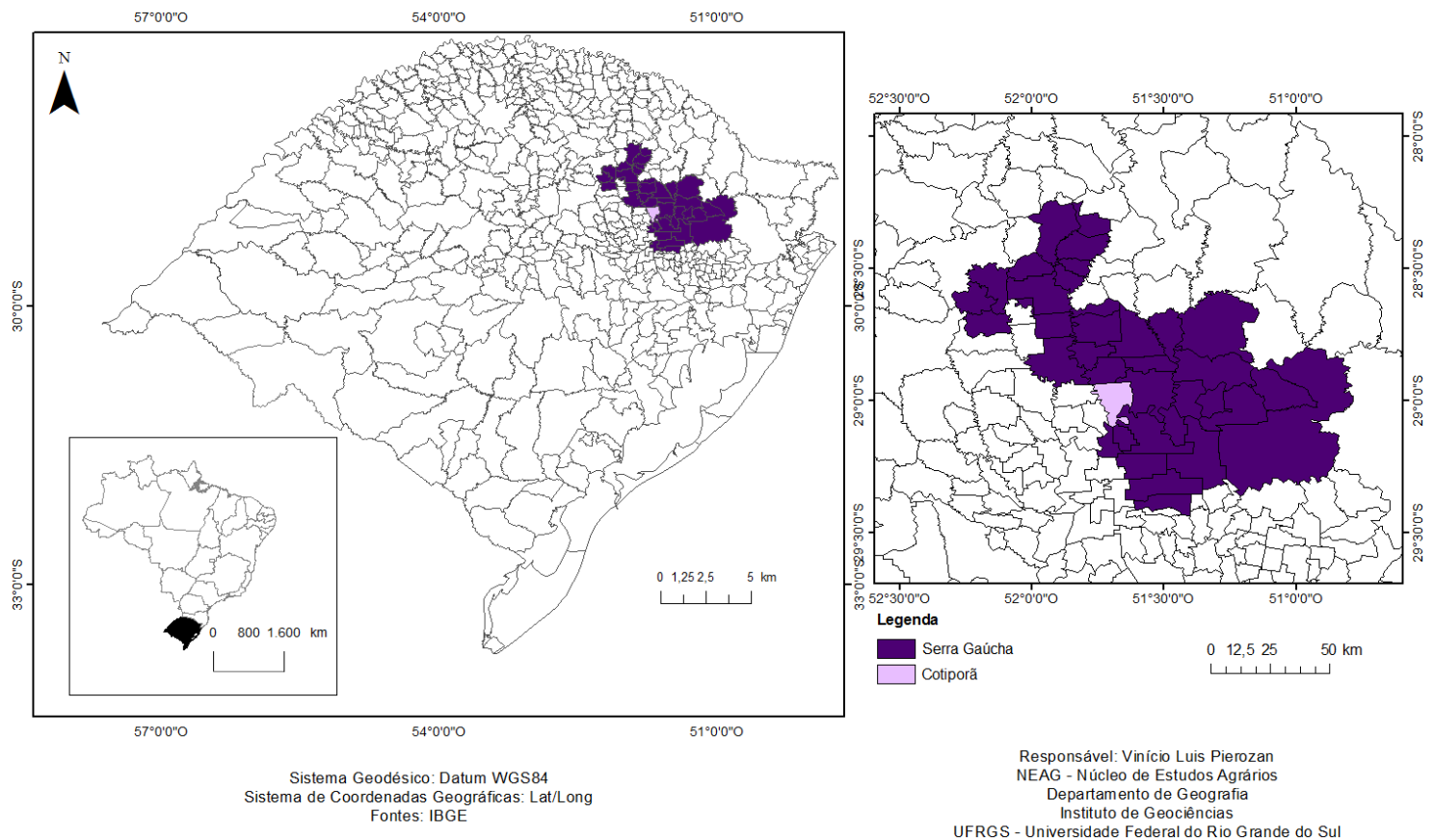

Figura 1. Localização da área de estudo. Fonte: Pierozan (2019).

A produção de uva é um cultivo agrícola muito presente em Cotiporã, sendo bastante importante também para a economia do município e para a manutenção do emprego no espaço rural, tendo em vista, que praticamente metade da população do município reside na área rural e tira o seu próprio sustento e de sua família da agricultura. Destaca-se que,

A cultura da uva é um legado da imigração italiana no município, o trabalho nos vinhedos em sua maior parte é realizado por descendentes de imigrantes italianos, que ali se instalaram e são oriundos da Região do Vêneto localizada no nordeste da Itália (MANFIO; PIEROZAN; MEDEIROS, 2019, p.39).

Com o passar dos anos e principalmente nas últimas duas décadas (1995-2015) a viticultura vem adquirindo cada vez mais relevância para a agricultura local, tendo em vista, que está aumentando significativamente a sua área cultivada (ha) com vinhedos (Gráfico 1) e produção (t) de uva (Gráfico 2). Atualmente a produção de uva constitui a principal atividade agrícola e a uva é a fruta mais cultivada no município. 


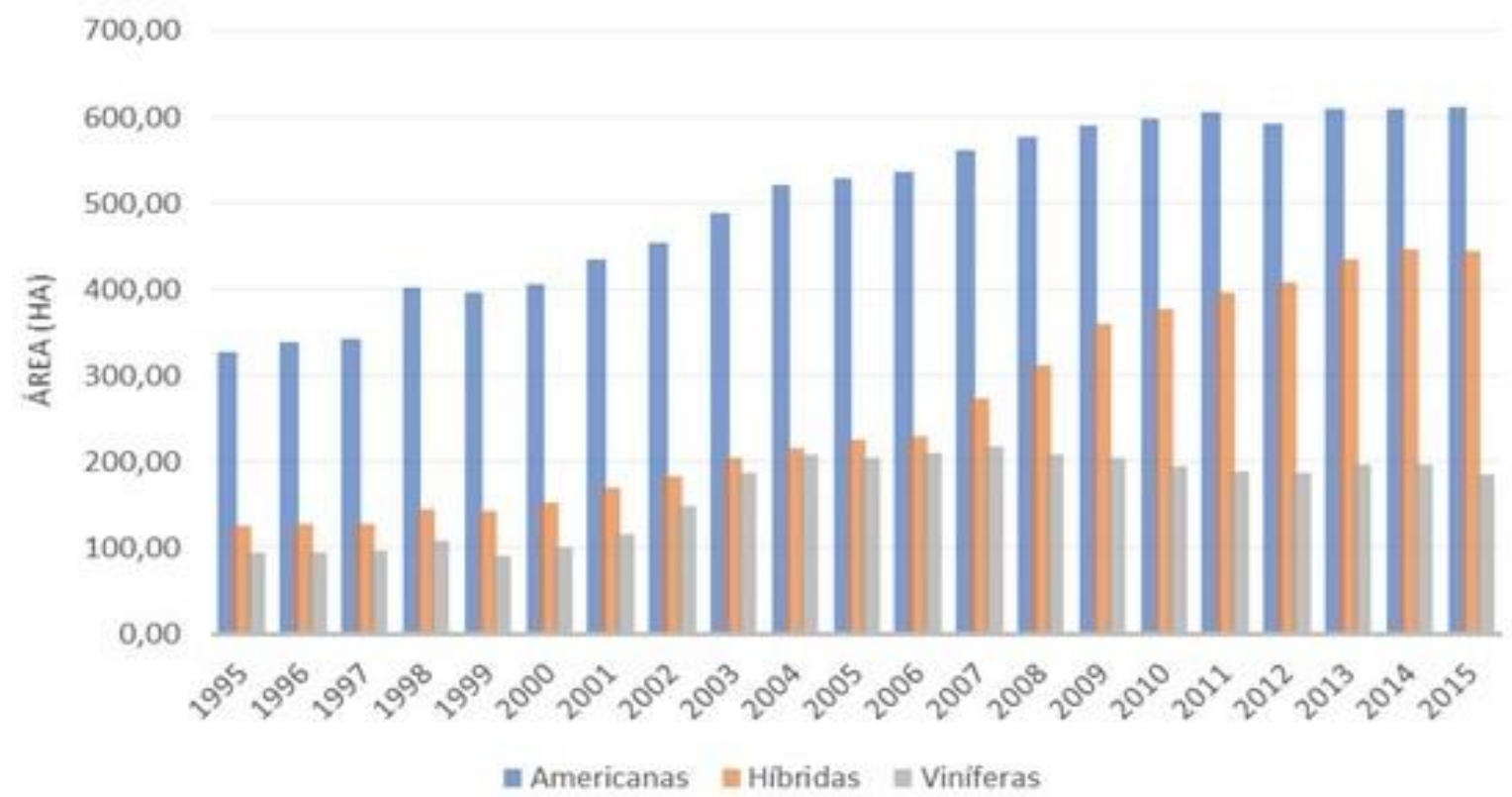

Gráfico 1. Área cultivada com vinhedos em Cotiporã (1995-2015). Fonte: Elaborado pelo próprio autor a partir de Mello et al., (2017b).

No que tange à área (ha) cultivada com parreiras percebe-se que ocorreu uma expansão bastante significativa de vinhedos nos últimos 20 anos, conforme pode ser observado no Gráfico 1. Em 1995, o município tinha uma área cultivada composta por 550,41 (ha), em 2015 os vinhedos passaram a ocupar uma área de aproximadamente $1.241,88$ (ha), nesse curto espaço de tempo a viticultura expandiu a sua área cultivada em $125,63 \%$, ou seja, os vinhedos mais que dobraram durante esse período.

As variedades cultivadas, praticamente, não sofreram alterações durante esse intervalo de tempo, é verificada uma especialização da viticultura realizada no município, composta pelas variedades americanas e híbridas desenvolvidas pelo Programa de Melhoramento Genético da EMBRAPA (Uva e Vinho), como as mais cultivadas pelos agricultores. As cultivares de uvas americanas - Vitis labrusca: Concord, Jacquez, Bordô, Niágara Branca e Niágara Rosada são as variedades mais cultivadas, já dentre as cultivares híbridas com maior área (ha) de vinhedos plantados estão as variedades: Isabel, Seibel 1077, Isabel Precoce, BRS Violeta, BRS Cora, BRS Lorena. A maior parte das uvas americanas e híbridas é destinada para a elaboração de sucos (Suco 100\% Natural Integral e Suco Orgânico), vinho de mesa, e uma parcela menor tem como finalidade, o consumo in natura.

As variedades viníferas de origem europeia, já na primeira metade da década de 2000 haviam dobrado a sua área cultivada (ha), porém desde então a expansão das variedades se estabilizou e não apresentam crescimento significativo, diferentemente das cultivares americanas e híbridas que continuam expandindo a sua área cultivada (ha). Em Cotiporã, as viníferas são as variedades menos cultivadas pelos agricultores. Porém, destacam-se os vinhedos plantados que pertencem as castas da espécie Vitis vinífera L: Alicante Bouschet, Chardonnay, Merlot, Prosecco e Cabernet Sauvignon. 
As uvas viníferas têm sua utilização concentrada na elaboração de vinhos finos e espumantes.

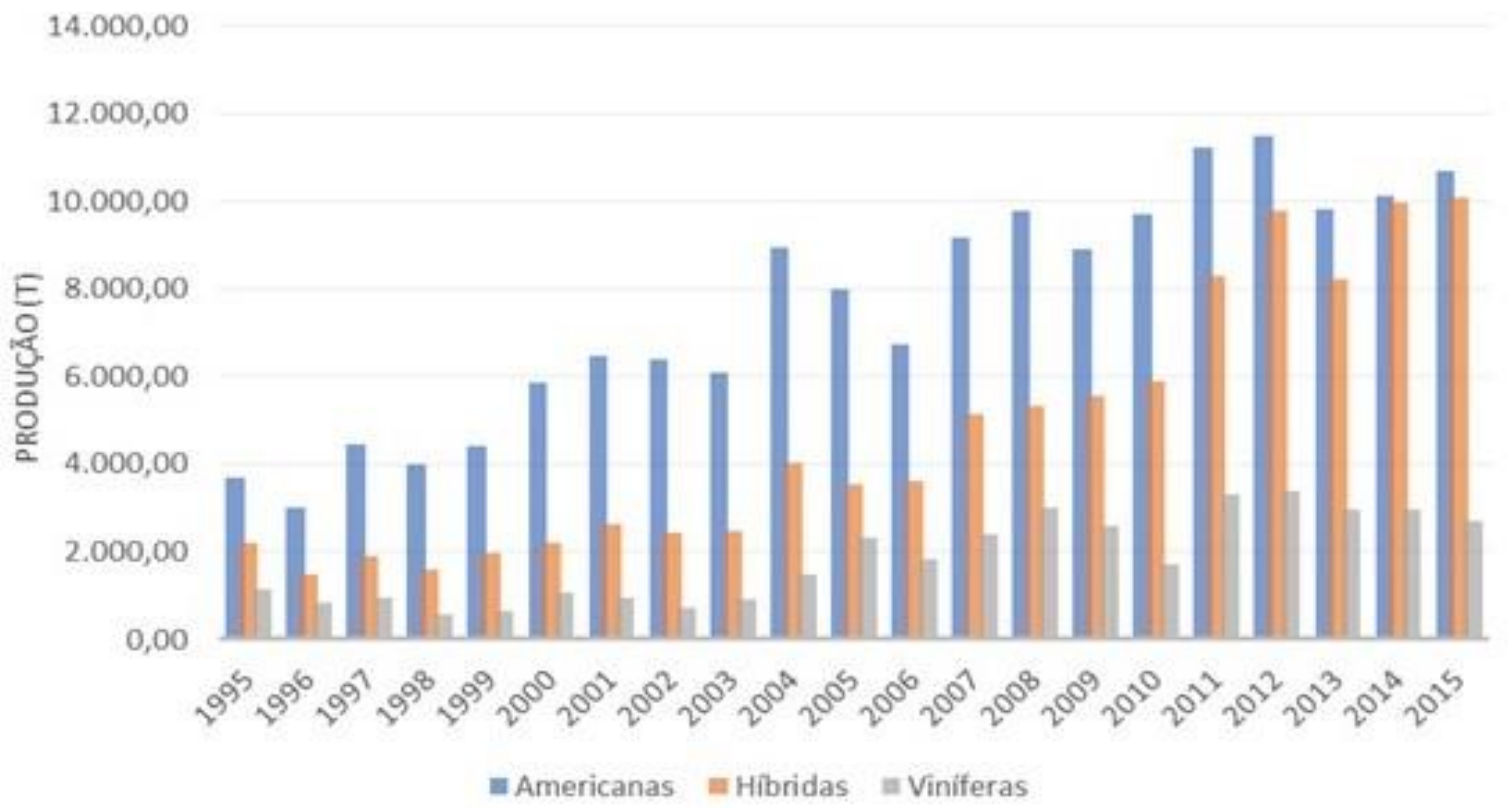

Gráfico 2. Produção de uva em Cotiporã (1995-2015). Fonte: Elaborado pelo próprio autor a partir de Mello et al., (2017b).

A uva produzida em Cotiporã é, cultivada dentro do modelo de agricultura convencional, que utiliza e/ou pode vir a usar nos vinhedos uma vasta gama de produtos tóxicos a fauna, a flora, ao agricultor e ao consumidor final da fruta. A legislação brasileira permite e assim o agricultor, bem como, qualquer interessado em produzir uvas desde que tenha o Talão de Produtor Rural ${ }^{13}$ para possibilitar a compra, tem

[...] à sua disposição para utilização 224 diferentes tipos (nomes comerciais) de agrotóxicos. Os venenos estão agrupados em diferentes categorias sendo 135 fungicidas, 43 inseticidas e acaricidas e 46 herbicidas, que possuem registro no Ministério da Agricultura, Pecuária e Abastecimento (MAPA) para serem utilizados na cultura da videira (PIEROZAN; MANFIO; MEDEIROS, 2018, p.2622).

Além dessa expressiva quantidade de venenos que os agricultores têm permissão legal para empregar nos vinhedos acrescentam-se também os adubos químicos, fertilizantes para o solo e para a vinha que são aplicados durante todo o ano nos

13 Documento que apresenta notas fiscais, sendo compostas por quatro vias. As notas fiscais são utilizadas para documentar todos os produtos que o agricultor comercializa. Consta na nota a descrição do produto em relação a quantidade, preço, variedade, embalagem. Atualmente o Talão de Produtor Rural está em processo gradativo de substituição pela Nota Fiscal Eletrônica (NF-e), que no Rio Grande do Sul tem como prazo final de transição o dia $1^{\circ}$ de janeiro de 2020.

REVISTA GEONORTE, V.10, N.36, p.17-35, 2019.

DOI: $10.21170 /$ geonorte.2019.V.10.N.34.A17.35

(ISSN 2237 - 1419) 
parreirais, mesmo no período de não produção, tendo em vista a produção de uva ser um cultivo perene.

A produção de uva orgânica no município é realizada por agricultores familiares em pequenas propriedades agrícolas que não ultrapassam os 20 (ha) cultivados com vinhedos. As principais variedades cultivadas no sistema orgânico são as cultivares de uvas comuns, Bordô, Rúbia e Concord, destinadas para a elaboração de suco e a variedade Niágara Branca que é utilizada para consumo in natura, como uva de mesa, mas pode ser utilizada também para a elaboração de suco e vinho de mesa. As demais cepas cultivadas no sistema orgânico são utilizadas como uvas de mesa em sua maioria como, por exemplo, a Rainha Itália, que no Brasil é a mais utilizada para essa finalidade, e as variedades Perlona, Benitaka, Red Globe, Rubi e Brasil.

Dos 10 agricultores entrevistados 8 deles passaram pelo processo de transição agroecológica e converteram os seus vinhedos do modelo convencional de produção para o orgânico. O processo de transição foi lento e gradual, começou com a eliminação dos agrotóxicos, que foram substituídos por produtos naturais elaborados pelos próprios agricultores para combater as pragas, ervas daninhas, mofo e demais enfermidades que atacam as videiras. Posteriormente, os adubos e fertilizantes industrializados também foram sendo eliminados das propriedades agrícolas e passaram a dar lugar a biofertilizantes e adubos orgânicos preparados na propriedade pelo próprio agricultor a partir de produtos naturais. O processo de eliminação dos produtos industrializados dos vinhedos levou um período de 36 meses para ser realizado de forma total pelos agricultores até a produção ser totalmente livre dos produtos químicos, tóxicos e a fauna, flora, solos se recuperarem dos venenos que foram utilizados anteriormente nos parreirais. Os outros 2 entrevistados tiveram os seus vinhedos concebidos desde a sua fase inicial de implantação sob o modelo de produção orgânica e não precisaram passar pelo processo de transição agroecológica.

Durante todo o processo de transição agroecológica os agricultores receberam em suas propriedades acompanhamento mensal de técnicos da EMATER-RS (escritório de Cotiporã) e Cooperativa de Sucos Monte Vêneto, que auxiliavam os agricultores a elaborarem os diferentes produtos e preparos naturais para serem aplicados nos vinhedos, bem como, técnicas de manejo para serem realizadas nas vinhas e para a preservação do solo. Somando-se a assistência recebida das instituições citadas acima a Prefeitura Municipal também viabilizou parceria com a ONG Centro Ecológico de Ipê (Núcleo Serra), que passou a visitar as unidades de produção agrícola dos produtores de uva cotiporanenses orientando, capacitando, estimulando e fornecendo todo o assessoramento necessário para realizar o processo de transição agroecológica com êxito e passar a produzir na forma orgânica, além de auxiliar nos tramites burocráticos exigidos para a obtenção da certificação.

A uva orgânica produzida em Cotiporã tem sua certificação realizada através da modalidade participativa, concedida pela Rede Ecovida de Agroecologia por intermédio do Centro Ecológico de Ipê (Núcleo Serra), que atua como parceiro da 
entidade. $\mathrm{O}$ custo $^{14}$ para a obtenção da certificação participativa é praticamente inexistente para o agricultor familiar, envolve apenas o pagamento dos procedimentos burocráticos (documentos), uma taxa irrisória quando comparada aos valores cobradas pelas empresas que realizam a certificação por auditoria.

\section{CONSIDERAÇÕES FINAIS}

A produção de uva orgânica que está sendo realizada no município de Cotiporã está se constituindo como um grande agente de transformação do espaço agrário local e, também está promovendo o fortalecimento do setor vitivinícola regional. Embora, a viticultura orgânica seja um sistema de cultivo agrícola recente no município e o cultivo da fruta em toda a região já é realizado há mais de 140 anos a produção orgânica está atraindo, ano após ano, cada vez mais agricultores favoráveis a este novo paradigma de produção.

Os agricultores adeptos da viticultura convencional que estão convertendo os seus vinhedos para o sistema orgânico buscam na produção sustentável várias vantagens, que o cultivo convencional não proporciona. Os principais benefícios obtidos pelos produtores de uva orgânica são: facilidade na comercialização da fruta, tanto in natura, quanto dos produtos elaborados a partir da uva, pois a demanda é maior que a oferta para esse tipo de produto; rentabilidade financeira, o agricultor recebe em média 40\% a mais pelo quilo da uva quando é comercializada com vinícolas e/ou demais empresas de beneficiamento e quando comercializada diretamente com o cliente na propriedade, ou em feiras de produtos orgânicos, o agricultor chega a receber mais de $100 \%$ do preço pelo quilo em relação ao que receberia se entregasse a fruta em estabelecimentos vitivinícolas; qualidade de vida, a eliminação dos agrotóxicos e demais produtos químicos nos parreiras segundo alguns produtores rurais proporcionou melhores condições de trabalho na propriedade e melhorou significativamente a saúde e o bem estar dos agricultores e de seus familiares.

Somando-se aos ganhos citados acima verificados diretamente pelos agricultores em suas unidades de produção agrícola, que dificilmente possuem mais de 20 (ha) destinados à produção de uva, destaca-se também o fortalecimento da agricultura familiar, que no município, bem como, em toda a Serra Gaúcha é formada pela pequena propriedade rural, estruturada na mão de obra familiar. A dedicação à produção de uva e a elaboração de vinho no município é uma atividade que se mantém preservada ao longo dos anos, se constitui num oficio que abriga diferentes gerações de uma mesma família e que com a inserção do cultivo orgânico passa a proporcionar melhores oportunidades aos agricultores para continuarem a manteremse na área rural.

\footnotetext{
${ }^{14}$ Informação obtida durante a Mesa Redonda "Agronegócio, ambiente e soberania alimentar no século XXI" ministrada pelo palestrante Dr. Marcos Aurélio Saquet (UNIOESTE) realizada durante o XXIV ENGA - Encontro Nacional de Geografia Agrária, ocorrido em Dourados, MS, entre os dias 06 e 10 de novembro de 2018.
}

REVISTA GEONORTE, V.10, N.36, p.17-35, 2019.

(ISSN 2237 - 1419) 


\section{REFERÊNCIAS}

ABREU, L. S. et al. Relações entre agricultura orgânica e agroecologia: desafios atuais em torno dos princípios da agroecologia. Revista Desenvolvimento e Meio Ambiente, Curitiba, v. 26, p. 143-160, jul./dez., 2012.

AB'SÁBER, A. Os Domínios de Natureza no Brasil: potencialidades paisagísticas. São Paulo: Editora Ateliê Editorial, 2003.

BOMBARDI, L. M. Geografia do Uso de Agrotóxicos no Brasil e Conexões com a União Europeia. São Paulo: FFLCH - USP, 2017. 296p.

BRASIL. Empresa Brasileira de Pesquisa Agropecuária (EMBRAPA Clima Temperado). Projeto Quintais Orgânicos de Frutas. Pelotas: EMBRAPA Clima Temperado, 2016. Disponível em: <https://www.embrapa.br/clima-temperado/buscade-noticias/-/noticia/12270297/projeto-quintais-organicos-faz-parte-de-indicacoes-deboas-praticas-sustentaveis-da-fao > . Acesso em: 26 de dezembro de 2018.

BRASIL. Instituto Brasileiro de Geografia e Estatística (IBGE). Atlas das Representações Literárias de Regiões Brasileiras. Volume 1. Rio de Janeiro: Fundação IBGE, 2006. Disponível em: $<$ http://geoftp.ibge.gov.br/atlas/tematicos/atlas_representacoes_literarias/vol_1_brasi I_meridional.pdf>. Acesso em: 07 de fevereiro de 2019.

BRASIL. Instituto Brasileiro de Geografia e Estatística (IBGE). Cotiporã-RS Mapa Municipal Estatístico. Rio de Janeiro: Fundação IBGE, 2011. Disponível em: $<$ http://geoftp.ibge.gov.br/cartas_e_mapas/mapas_para_fins_de_levantamentos_est atisticos/censo_demografico_2010/mapas_municipais_estatisticos/rs/cotipora_v2.pdf >. Acesso em: 28 de dezembro de 2018.

BRASIL. Instituto Brasileiro de Geografia e Estatística (IBGE). IBGE Cidades Cotiporã (RS). Rio de Janeiro: Fundação IBGE, 2010. Disponível em: $<$ https://cidades.ibge.gov.br/brasil/rs/cotipora/panorama>. Acesso em: 07 de fevereiro de 2019.

CAETANO, M. Vinho natureba pede passagem. Dinheiro Rural, São Paulo, v. 1, 2017. Disponível em: <https://www.dinheirorural.com.br/vinho-natureba-pede-passagem/>. Acesso em: 18 de dezembro de 2018.

CAMARGO, U. A.; TONIETTO, J.; HOFFMANN, A. Progressos na Viticultura Brasileira. Revista Brasileira de Fruticultura, Jaboticabal, v. especial, p. 144-149, 2011.

CELENTANO, M. O Mundo dos Vinhos Orgânicos. Disponível em: $<$ http://planetaorganico.com.br/site/index.php/o-mundo-dos-vinhos-organicos-2/>. Acesso em: 18 de dezembro de 2018. 
CONTERATO, M. A.; FILIPI, E. E. Teorias do Desenvolvimento. Porto Alegre: Editora da UFRGS, 2009.

CONSELHO BRASILEIRO DA PRODUÇÃO ORGÂNICA E SUSTENTÁVEL (ORGANIS). Consumo de Produtos orgânicos no Brasil: primeira pesquisa nacional sobre o consumo de orgânicos. Curitiba: Organis/Market Analysis, 2017. Disponível em: $\quad$ https://organis.org.br/wp-content/uploads/2018/11/Pesquisa-Consumo-deProdutos-Orga\%CC\%82nicos-no-Brasil.pdf>. Acesso em: 2 de janeiro de 2019.

DE-POLLI, H. et al. A pesquisa em agricultura orgânica frente às demandas da sociedade. In: SIMPÓSIO BRASILEIRO SOBRE AGROPECUÁRIA ECOLÓGICA E SAÚDE HUMANA, I., 2000, Rio de Janeiro. Anais... Rio de Janeiro: Universidade Federal Fluminense (UFF), 2000. 3p.

EDUARDO, M. F.; FINATTO, R. A. A territorialização da agroecologia no Paraná. In: ENCONTRO NACIONAL DE GEOGRAFIA AGRÁRIA, ENGA, XXIV., 2018, Dourados, de 06 a 10 de nov., 2018. Anais eletrônicos... Dourados: UFGD, 2018. p.2500-2519. Disponível em: <https://drive.google.com/file/d/1ZMaVtvLIII3hB8hm_ogUJ526PSLWh-sY/view>. Acesso em: 16 de fevereiro de 2019.

FEDERAÇÃO DAS COOPERATIVAS VINÍCOLAS DO RIO GRANDE DO SUL (FECOVINHO). Viticultura Biodinâmica na Serra Gaúcha: projeto Piloto. Bento Gonçalves: FECOVINHO/IBRAVIN, 2016.

FREITAS, B. M. C.; BOMBARDI, L. M. A política nacional de irrigação e o uso de agrotóxicos no Brasil: contaminação e intoxicações no Ceará. Revista GEOgraphia, Niterói, v. 20, n. 43, p. 86-100, mai./ago., 2018.

GARRIDO, L. da. R.; JUNIOR, W. S. Apresentação. In: NACHTIGAL, J. C. et al. Recomendações para produção de uvas de mesa em cultivo protegido na Região da Serra Gaúcha. Documentos, n.70. Bento Gonçalves: Embrapa Uva e Vinho, 2010

GIOVANNINI, E. Uva Agroecológica. Porto Alegre: Editora Renascença, 2001.

INSTITUTO BRASILEIRO DO VINHO (IBRAVIN). Safra de uva 2017 é recorde no Rio Grande do Sul. Disponível em: <https://www.ibravin.org.br/Noticia/safra-de-uva-2017e-recorde-no-rio-grande-do-sul/281>. Acesso em: 08 de fevereiro de 2019.

LUIZZI, D.; FERREIRA, J. D.; SCHNEIDER, M. B. O Comércio Internacional de produtos Orgânicos: atuação do Brasil e de países atuantes no setor. Caderno de Administração, Maringá, v. 24, n. 2, p. 72-88, 2016.

MACHADO L. C. P.; MACHADO FILHO, L. C. P. A Dialética da Agroecologia: contribuição para um mundo com alimentos sem veneno. São Paulo: Editora Expressão Popular, 2014. 360p. 
MANFIO, V.; PIEROZAN, V. L.; MEDEIROS, R. M. V. A produção de uva orgânica no estado do Rio Grande do Sul: as experiências dos agricultores familiares de Cotiporã e Dom Pedrito. Para Onde!?, Porto Alegre, v. 11, n. 1, p. 36-44, 2019.

MARX, K. O Capital. Livro 1. São Paulo: Editora Abril Cultural, 1982.

MATTE, A.; WAQUIL, P. D.; NESKE, M. Z. Dinâmicas socioeconômicas e produtivas das microrregiões Campanha Meridional e Serra do Sudeste - RS. In: ENCONTRO DE ECONOMIA GAÚCHA, VII., 2014, Porto Alegre, 15 e 16 de mai., 2014. Anais Eletrônicos... Porto Alegre: FEE, 2014. Disponível em: <ttps://www.fee.rs.gov.br/wpcontent/uploads/2014/05/201405267eeg-mesa21-

dinamicassocioeconomicasprodutivasmicroregioescampanhameridional.pdf $>$.

Acesso em: 22 de julho de 2019.

MEDEIROS, R. M. V.; LINDNER, M. A Territorialização de Assentamentos e Reassentamentos no Rio Grande do Sul: os espaços de vida no contexto da luta pela terra. Revista FSA (Faculdade Santo Agostinho), Teresina, v. 11, n. 2, p. 261-273, abr./jun., 2014.

MEIRELES, L. R.; RUPP, L. C. D. Agricultura Ecológica: princípios básicos. Ipê: Publicação interna do Centro Ecológico de Ipê (Núcleo Serra), 2014. Disponível em: <http://www.centroecologico.org.br/agricultura.php>. Acesso em: 27 de dezembro de 2018.

MELLO, L. M. R. de. et al. Dados cadastrais da viticultura do Rio Grande do Sul: 2013 a 2015. In: MELLO, L. M. R. de. et al. Cadastro Vitícola do Rio Grande do Sul - 2013 a 2015. Bento Gonçalves: Embrapa Uva e Vinho, 2017. Disponível em: <http://www.cnpuv.embrapa.br/cadastro-viticola/rs-2013-

2015/dados/dados_cadastrais_descricao.html>. Acesso em: 30 de dezembro de 2018a.

MELLO, L. M. R. de. et al. Cadastro Vitícola do Rio Grande do Sul - 2013 a 2015. Dados Cadastrais do Município de Cotiporã. Bento Gonçalves: Embrapa Uva e Vinho, 2017. Disponível em: <http://www.cnpuv.embrapa.br/cadastro-viticola/rs20132015/dados_cadastrais_descricao.html>. Acesso em: 25 de dezembro de 2018b.

MELO, G. W. B.; BOTTON, M.; GARRIDO, L. R. Produção orgânica de uva para mesa. Documentos, n.92. Bento Gonçalves: Embrapa Uva e Vinho, 2015.

PADOVAN, M. P. Agricultura Familiar é Responsável por $70 \%$ dos Alimentos que Chegam à Nossa Mesa. Disponível em: $<$ https://www.miltonpadovan.com.br/blog/agriculturafamiliar70dosalimentos/>. Acesso em: 08 de fevereiro de 2019.

PELAEZ, V. Monitoramento do Mercado do Agrotóxicos. Disponível em: <http://portal.anvisa.gov.br/wps/wcm/connect/c4bdf280474591ae99b1dd3fbc4c6735/ estudo_monitoramento.pdf?MOD=AJPERES>. Acesso em: 27 de dezembro de 2018. 
PIEROZAN, V. L.; MANFIO, V. A Viticultura orgânica no Rio Grande do Sul: o caso da transformação de espaço agrário de Cotiporã e Dom Pedrito. In: ENCONTRO NACIONAL DE GEOGRAFIA AGRÁRIA, ENGA, XXIII., 2016, São Cristóvão, de 09 a 13 de nov., 2016. Anais... São Cristóvão: UFSE, 2016. CD-ROM.

PIEROZAN, V. L.; MANFIO, V.; MEDEIROS, R. M. V. Vitivinicultura orgânica no Rio Grande do Sul: a expansão da produção sustentável de uva, vinho e suco em Cotiporã e Dom Pedrito. In: ENCONTRO NACIONAL DE GEOGRAFIA AGRÁRIA, ENGA, XXIV., 2018, Dourados, de 06 a 10 de nov., 2018. Anais eletrônicos... Dourados: UFGD, 2018. $\quad$ p. 2618-2631. Disponível em: <https://drive.google.com/file/d/1ZMaVtvLIII3hB8hm_ogUJ526PSLWh-sY/view>. Acesso em: 27 de dezembro de 2018.

QUEIROZ, M. A. C. de. A difusão da agricultura orgânica de base agroecológica: uma discussão sobre as experiências de Río Cuarto (Argentina) e Seropédica (Brasil). Tese (Doutorado em Ciência, Tecnologia e Inovação em Agropecuária). Pró-Reitora de Pesquisa e Pós-Graduação, Universidade Federal Rural do Rio de Janeiro, Seropédica, Rio de Janeiro, 2014. 141f.

SAQUET, M. A. Agronegócio, ambiente e soberania alimentar no século XXI. Mesa Redonda proferida no XXIV ENGA - Encontro Nacional de Geografia Agrária, Dourados, 7 nov. 2018.

TAVARES DOS SANTOS, J. V. Colonos do Vinho: estudo sobre a subordinação do trabalho camponês ao capital. São Paulo: Editora Hucitec, 1978.

TOLEDO, V.; BARRERA-BASSOLS, N. A memória biocultural: a importância ecológica das sabedorias tradicionais. Tradução de Rosa L. Peralta. São Paulo: Editora Expressão Popular, 2015. 272p.

VILELA, G. F. et al. Agricultura orgânica no Brasil: um estudo sobre o Cadastro Nacional de Produtores Orgânicos. Documentos, n. 127. Campinas: Embrapa Territorial, 2019. 20p. 